\title{
DONOR-MATCHED MESENCHYMAL STEM CELLS FROM KNEE INFRAPATELLAR AND SUBCUTANEOUS ADIPOSE TISSUE OF OSTEOARTHRITIC DONORS DISPLAY DIFFERENTIAL CHONDROGENIC AND OSTEOGENIC COMMITMENT
}

\author{
S. Lopa ${ }^{1}$, A. Colombini², D. Stanco ${ }^{3}$, L. de Girolamo ${ }^{3}$, V. Sansone ${ }^{4,5}$ and M. Moretti ${ }^{1}$,* \\ ${ }^{1}$ Cell and Tissue Engineering Laboratory, IRCCS Galeazzi Orthopaedic Institute, Milan, Italy \\ ${ }^{2}$ Laboratory of Experimental Biochemistry and Molecular Biology, IRCCS Galeazzi Orthopaedic Institute, Milan, Italy \\ ${ }^{3}$ Orthopaedics Biotechnology Laboratory, IRCCS Galeazzi Orthopaedic Institute, Milan, Italy \\ ${ }^{4}$ Department of Biomedical Sciences for Health, University of Milano, Milan, Italy \\ ${ }^{5}$ Orthopaedic Department, IRCCS Galeazzi Orthopaedic Institute, Milan, Italy
}

\begin{abstract}
Cell-based therapies have recently been proposed for the treatment of degenerative articular pathologies, such as early osteoarthritis, with an emphasis on autologous mesenchymal stem cells (MSCs), as an alternative to terminally differentiated cells. In this study, we performed a donor-matched comparison between infrapatellar fat pad MSCs (IFP-MSCs) and knee subcutaneous adipose tissue stem cells (ASCs), as appealing candidates for cell-based therapies that are easily accessible during surgery.

IFP-MSCs and ASCs were obtained from 25 osteoarthritic patients undergoing total knee replacement and compared for their immunophenotype and differentiative potential.

Undifferentiated IFP-MSCs and ASCs displayed the same immunophenotype, typical of MSCs $\left(\mathrm{CD} 13^{+} / \mathrm{CD} 29^{+} /\right.$ $\mathrm{CD}_{4} 4^{+} / \mathrm{CD} 3^{+} / \mathrm{CD} 90^{+} / \mathrm{CD} 105^{+} / \mathrm{CD} 166^{+} / \mathrm{CD} 31^{-} / \mathrm{CD} 45^{-}$). IFP-MSCs and ASCs showed similar adipogenic potential, though undifferentiated ASCs had higher $L E P$ expression compared to IFP-MSCs $(p<0.01)$. Higher levels of calcified matrix $(p<0.05)$ and alkaline phosphatase $(p<0.05)$ in ASCs highlighted their superior osteogenic commitment compared to IFP-MSCs. Conversely, IFP-MSCs pellets showed greater amounts of glycosaminoglycans $(p<0.01)$ and superior expression of $A C A N(p<0.001)$, SOX9, COMP $(p<0.001)$ and COL2A1 $(p<0.05)$ compared to ASCs pellets, revealing a superior chondrogenic potential. This was also supported by lower COL10A1 $(p<0.05)$ and COL1A1 $(p<0.01)$ expression and lower alkaline phosphatase release $(p<0.05)$ by IFP-MSCs compared to ASCs.

The observed dissimilarities between IFP-MSCs and ASCs show that, despite expressing similar surface markers, MSCs deriving from different fat depots in the same surgical site possess specific features. Furthermore, the in vitro peculiar commitment of IFP-MSCs and ASCs from osteoarthritic donors towards the chondrogenic or osteogenic lineage may suggest a preferential use for cartilage and bone cell-based treatments, respectively.
\end{abstract}

Keywords: Mesenchymal stem cell, cartilage, bone, infrapatellar fat pad, adipose tissue, cell-based therapy, osteoarthritis.

*Address for correspondence:

Matteo Moretti

Cell and Tissue Engineering Laboratory

IRCCS Galeazzi Orthopaedic Institute

Via R. Galeazzi 4, 20161 Milan, Italy
Phone Number: +39 0266214049

FAX Number: +390266214060

E-mail: matteo.moretti@grupposandonato.it

\section{Introduction}

The low self-repair ability of articular cartilage and the lack of treatments that can reproducibly restore defects at the bone-cartilage interface provide a major reason for the development of cell-based therapies for bone and cartilage repair (Beane and Darling, 2012; Mohal et al., 2012; Szpalski et al., 2012). Joint replacement, considered a successful and standard procedure in the treatment of elderly patients affected by osteoarthritis (OA), is controversial in patients considered too young or active for conventional arthroplasty, who experience higher implant failure rates and earlier revisions (Harrysson et al., 2004; Julin et al., 2010). Thus, cell-based therapies have been recently proposed also for the treatment of middle-aged early OA patients to alter the progression of this degenerative disease, with the hope of obviating or at least delaying the need for joint replacement (Gomoll et al., 2012).

Mesenchymal stem cells (MSCs) have been investigated as an alternative to terminally differentiated cells to develop novel treatments for bone and cartilage defects, since they can be easily harvested from several adult tissues and are able to differentiate towards the osteogenic and chondrogenic lineages (Johnstone et al., 1998; Pittenger et al., 1999). Beside bone marrow MSCs (BMSCs), more recently adipose derived mesenchymal stem cells have been successfully used for bone and cartilage applications (Rada et al., 2009; Jung et al., 2010; Rhee et al., 2011; Kang et al., 2012; Choi et al., 2014). In particular, MSCs resident in the infrapatellar fat pad (IFP-MSCs) and knee subcutaneous adipose tissue (ASCs) can be considered appealing alternative cell sources for articular cell-based therapies, thanks to their differentiative potential and ease of harvesting during knee surgery, which causes minimal additional morbidity to patients. Furthermore, the fast protocol employed in their isolation is advantageous in view of a future one-step surgical cell-based treatment.

Beneficial effects have been observed when treating animals with induced OA with MSCs derived from different adipose depots, with cells playing a key role in the inhibition of OA progression and in the restoration of damaged cartilage (Toghraie FS et al., 2011; ter Huurne 
et al., 2012; Toghraie F et al., 2012; Desando et al., 2013). Moreover, it has been demonstrated that intra-articular injection of IFP-MSCs leads to relief of pain symptoms and to improvement in knee functions in patients suffering from knee OA (Koh et al., 2013).

Several studies have characterised the multi-lineage potential and immunophenotype of IFP-MSCs (Dragoo et al., 2003; Wickham et al., 2003; English et al., 2007; Khan et al., 2009; Liu et al., 2012; Lopez-Ruiz et al., 2013), but - to our knowledge - only few studies have reported a preliminary comparison of mesenchymal stem cells from infrapatellar fat pad and knee subcutaneous adipose tissue (Mochizuki et al., 2006; Alegre-Aguaron et al., 2012; Pires de Carvalho et al., 2012). Nevertheless, in these few comparative studies, the evaluation of osteogenic and chondrogenic potential has been performed mainly by qualitative histological stainings, without investigating gene expression profiles (Alegre-Aguaron et al., 2012; Pires de Carvalho et al., 2012), and the comparison was restricted to very few donors (Mochizuki et al., 2006), limiting the clinical relevance of the findings.

In the present study, to evaluate the different and specific relevance of IFP-MSCs and ASCs for orthopaedic cell-based therapies, we compared the features and the multi-differentiative potential of cells derived from $25 \mathrm{OA}$ patients undergoing total knee replacement. To eliminate the common issue of inter-donor variability, we performed a donor-matched evaluation, harvesting and comparing both IFP-MSCs and ASCs from the same patient and focusing on their osteogenic and chondrogenic potential through multiple, quantitative analyses, and evaluating also the expression of hypertrophic and fibrocartilaginous markers in chondrogenic differentiated cells.

\section{Materials and Methods}

\section{Cell isolation and expansion}

Infrapatellar fat pad and subcutaneous adipose tissue were harvested from the knee of 25 patients affected by OA (mean age $70 \pm 8$ years, range $54-85$ years) during total knee replacement, with patients' informed consent and with the approval of the Institutional Review Board.

Inclusion criteria were: male and female gender, age between 50 and 85 years, grade III and IV knee osteoarthritis according to the Kellgren-Lawrence grading scale, indication for total knee replacement. Exclusion criteria were: rheumatoid arthritis, autoimmune diseases, systemic diseases, tumours, previous implant at the same knee and medical contraindication to elective surgery.

The infrapatellar fat pad appeared as a mixture of yellow adipose and white fibrous tissue. Based on the different colour and tissue consistence, we carefully separated the adipose fraction to proceed with IFP-MSCs isolation. The subcutaneous adipose tissue appeared as yellow tissue. No macroscopic signs of hypertrophy were observed in the samples.

IFP-MSCs were isolated from infrapatellar fat pad as previously described (Lopa et al., 2011). Briefly, adipose tissue was carefully separated from the synovium and minced into small pieces. The sample was then enzymatically digested $\left(37^{\circ} \mathrm{C}, 30 \mathrm{~min}\right)$ by $0.075 \%$ type I collagenase (Worthington Biochemical Co, Lakewood, NJ, USA). After digestion, the sample was centrifuged (1200 g, $10 \mathrm{~min}$ ) and filtered through a cell strainer (100 $\mu \mathrm{m}$ pores) to remove undigested tissue. Cells were counted by Trypan blue exclusion and plated in control medium consisting of high glucose DMEM (HG-DMEM, Life Technologies, Carlsbad, CA, USA) supplemented with $10 \%$ foetal bovine serum (FBS, Lonza, Basel, Switzerland), $0.029 \mathrm{mg} / \mathrm{mL}$ L-glutamine, $100 \mathrm{U} / \mathrm{mL}$ penicillin, $100 \mu \mathrm{g} / \mathrm{mL}$ streptomycin, $10 \mathrm{mM}$ HEPES, $1 \mathrm{mM}$ sodium pyruvate (all from Life Technologies) at approximately $10^{4}$ cells $/ \mathrm{cm}^{2}\left(37^{\circ} \mathrm{C}, 5 \% \mathrm{CO}_{2}\right)$. The same protocol was used to isolate ASCs from knee subcutaneous adipose tissue. Non-adherent cells were removed with the first medium refreshment. During culture, medium was changed twice a week. When IFP-MSCs and ASCs were about $90 \%$ confluent, they were detached using $0.05 \%$ trypsin/0.053 mM EDTA (Life Technologies) and plated at $3 \times 10^{3}$ cells $/ \mathrm{cm}^{2}$ for the following passages.

\section{Clonogenic ability assay}

A colony-forming unit-fibroblast (CFU-F) assay was performed to assess the clonogenic ability of IFP-MSCs and ASCs (Staszkiewicz et al., 2010). Cells were plated at different low densities (range, $48-1$ cells $/ \mathrm{cm}^{2}$ ) and cultured in control medium with $20 \%$ FBS. After 10 days, cells were fixed with $10 \%$ neutral buffered formalin and stained with Gram's crystal violet (Sigma-Aldrich, St. Louis, MO, USA). CFU-F frequency was established by scoring the individual colonies and expressing them as a percentage relative to the number of seeded cells.

\section{Flow cytometry for the assessment of typical MSCs surface markers}

At passage 4 (45-50 days of expansion, corresponding to 5-6 doublings from $\mathrm{P} 1$ to $\mathrm{P} 4$ with a doubling time ranging from 0.10 to 0.18 doublings/day), surface marker expression was evaluated by flow cytometry. IFP-MSCs and ASCs were detached using $0.05 \%$ trypsin $/ 0.53 \mathrm{mM}$ EDTA and washed twice in cold Fluorescence-Activated Cell Sorting (FACS) Buffer (phosphate-buffered saline (PBS) without $\mathrm{Ca}^{2+} / \mathrm{Mg}^{2+}$ containing $2 \%$ foetal bovine serum (FBS) and $0.1 \% \mathrm{NaN}_{3}$ ). For each sample, $2.5 \times 10^{5}$ cells were incubated for $30 \mathrm{~min}$ with the following antihuman primary monoclonal antibodies: CD13-FITC, CD29-biotinylated, CD31-FITC, CD34-biotinylated, CD44-FITC, CD45-FITC, CD105-biotinylated, CD106FITC, CD166-FITC (all from Ancell Corporation, Bayport, MN, USA), CD90-FITC and CD73-PE (from Miltenyi Biotec, Bergisch Gladbach, Germany), and CD151 (R\&D Systems, Minneapolis, MN, USA). After incubation, cells were washed with FACS buffer to remove the excess of primary antibody. Cells stained with biotinylated antibodies were incubated for $20 \mathrm{~min}$ with streptavidin-PE (Ancell Corporation), whereas samples stained with anti-CD151 primary antibody were incubated with a FITC-conjugated goat anti-mouse secondary antibody (Ancell Corporation). After incubation, cells were washed with FACS Buffer and suspended in $500 \mu \mathrm{L}$ of FACS buffer for analysis. Background fluorescence was established by negative 
controls and data were acquired using a FACSCalibur flow cytometer (BD Biosciences, Franklin Lakes, NJ, USA) collecting a minimum of 10,000 events. Analysis was performed using CellQuest software (BD Biosciences).

\section{Adipogenic differentiation}

IFP-MSCs and ASCs at passage 4 were plated at $3 \times 10^{3}$ cells $/ \mathrm{cm}^{2}$ and differentiated for 14 days in adipogenic medium using a repeated pulsed induction (de Girolamo et al., 2009) with 3 days of induction in control medium supplemented with $1 \mu \mathrm{M}$ dexamethasone, $10 \mu \mathrm{g} / \mathrm{mL}$ insulin, $500 \mu \mathrm{M} 3$-isobutyl-1-methylxanthine and $200 \mu \mathrm{M}$ indomethacin (all from Sigma-Aldrich), followed by 3 days of maintenance in control medium supplemented with $10 \mu \mathrm{g} / \mathrm{mL}$ insulin.

The production of lipid vacuoles was quantified by Oil Red O staining. Cells were fixed in $10 \%$ neutral buffered formalin for $10 \mathrm{~min}$, washed with $60 \%$ isopropanol, and stained with $8.5 \mathrm{mM}$ Oil Red O (Sigma-Aldrich) for 15 min. After rinsing with $\mathrm{ddH}_{2} \mathrm{O}$, Oil Red $\mathrm{O}$ was unstained with $100 \%$ isopropanol and absorbance was read at $490 \mathrm{~nm}$ (Perkin Elmer Victor X3 microplate reader; Perkin Elmer, Waltham, MA, USA).

\section{Osteogenic differentiation}

IFP-MSCs and ASCs at passage 4 were plated at $3 \times 10^{3}$ cells $/ \mathrm{cm}^{2}$ and differentiated for 14 or 21 days in osteogenic medium (de Girolamo et al., 2009) consisting of control medium supplemented with $10 \mathrm{mM}$ glycerol-2-phosphate, $10 \mathrm{nM}$ dexamethasone, $150 \mu \mathrm{M}$ L-ascorbic acid-2phosphate and $10 \mathrm{~nm}$ cholecalciferol (all from SigmaAldrich).

Calcified matrix deposition was measured using Alizarin Red-S staining. Cells were rinsed with PBS, fixed with ice-cold $70 \%$ ethanol for $1 \mathrm{~h}$ and stained with $40 \mathrm{mM}$ Alizarin Red-S (pH 4.1, Sigma-Aldrich) for $15 \mathrm{~min}$. After washing with $\mathrm{ddH}_{2} \mathrm{O}$, samples were unstained for 30 min with $10 \%$ cetylpyridinium chloride monohydrate (CPC, Sigma-Aldrich) in 0.1 M phosphate buffer ( $\mathrm{pH} 7.0$ ). Absorbance was read at $570 \mathrm{~nm}$ (Perkin Elmer Victor X3 microplate reader).

Alkaline phosphatase activity (ALP) was quantified by enzymatic assay (Bodo et al., 2002). Cells were rinsed with PBS and lysed in $0.1 \%$ Triton X-100 (Sigma-Aldrich). ALP was quantified by incubating cellular lysates at $37^{\circ} \mathrm{C}$ with $1 \mathrm{mM}$ p-nitrophenylphosphate (Sigma-Aldrich) in alkaline buffer $(100 \mathrm{mM}$ diethanolamine and $0.5 \mathrm{mM}$ $\mathrm{MgCl}_{2}, \mathrm{pH}$ 10.5). The enzymatic reaction was stopped with $1 \mathrm{~N} \mathrm{NaOH}$ and absorbance was read at $410 \mathrm{~nm}$ (Perkin Elmer Victor X3 microplate reader). ALP activity was normalised on total protein content, determined by BCA Protein Assay Kit (Pierce Biotechnology, Rockford, IL, USA), and expressed as ALP Units per mg of proteins.

\section{Chondrogenic differentiation}

Chondrogenic differentiation was performed by pellet culture. At passage 4, 4 × $10^{5}$ IFP-MSCs and ASCs were centrifuged $(250 \mathrm{~g}, 5 \mathrm{~min})$ to obtain cell pellets. Pellets were cultured for 14 days in chondrogenic medium (Barbero et al., 2004) consisting of HG-DMEM supplemented with $0.029 \mathrm{mg} / \mathrm{mL}$ L-glutamine, $100 \mathrm{U} / \mathrm{mL}$ penicillin, $100 \mu \mathrm{g} / \mathrm{mL}$ streptomycin, $10 \mathrm{mM}$ HEPES, $1 \mathrm{mM}$ sodium pyruvate, $1.25 \mathrm{mg} / \mathrm{mL}$ human serum albumin (all from Sigma-Aldrich), $1 \%$ ITS +1 (1.0 mg/mL insulin from bovine pancreas, $0.55 \mathrm{mg} / \mathrm{mL}$ human transferrin, $0.5 \mu \mathrm{g} /$ $\mathrm{mL}$ sodium selenite, $50 \mathrm{mg} / \mathrm{mL}$ bovine serum albumin and $470 \mu \mathrm{g} / \mathrm{mL}$ linoleic acid, Sigma-Aldrich), 0.1 $\mu \mathrm{M}$ dexamethasone, 0.1 mM L-ascorbic acid-2-phosphate and 10 ng/mL TGF- $\beta 1$ (Peprotech, Rocky Hill, New Jersey, USA).

For histological analysis, pellets were fixed for $24 \mathrm{~h}$ in $10 \%$ neutral buffered formalin, embedded in paraffin and sectioned at $4 \mu \mathrm{m}$. Sections were stained with haematoxylin-eosin (Sigma-Aldrich) and Alcian Blue ( $\mathrm{pH} 2.5$, Sigma-Aldrich) to evaluate extracellular matrix and glycosaminoglycans (GAGs) deposition.

For GAGs quantification, pellets were digested $(16 \mathrm{~h}$, $\left.60{ }^{\circ} \mathrm{C}\right)$ in $500 \mu \mathrm{L}$ of PBE buffer $\left(100 \mathrm{mM} \mathrm{Na}_{2} \mathrm{HPO}_{4}, 10 \mathrm{mM}\right.$ NaEDTA, pH 6.8) containing $1.75 \mathrm{mg} / \mathrm{mL}$ L-cysteine (Sigma-Aldrich) and $14.2 \mathrm{U} / \mathrm{mL}$ papain (Worthington). Samples were incubated with $16 \mathrm{mg} / \mathrm{L}$ dimethylmethylene blue (Sigma-Aldrich) and absorbance was read at $500 \mathrm{~nm}$ (Perkin Elmer Victor X3 microplate reader). The same samples were used for DNA quantification by CyQUANT Kit (Life Technologies).

Soluble ALP activity released in culture supernatants was measured by enzymatic assay. At the moment of medium refresh, culture supernatant was collected from each pellet and $50 \mu \mathrm{L}$ of medium were incubated with $1 \mathrm{mM}$ p-nitrophenylphosphate. The release of ALP was determined at early phase (day 0 to day 3 ) and late phase (day 11 to day 14) of chondrogenic differentiation.

\section{Gene expression analysis}

After 14 days of adipogenic, osteogenic or chondrogenic differentiation, gene expression was evaluated by real time PCR (Rotor Gene RG3000 system, Qiagen, Venlo, Netherlands). Total RNA was purified from cell lysates using the RNeasy Mini kit (Qiagen) and reversetranscribed to cDNA $\left(5 \mathrm{~min}\right.$ at $25^{\circ} \mathrm{C}, 30 \mathrm{~min}$ at $42{ }^{\circ} \mathrm{C}$ and $5 \mathrm{~min}$ at $85^{\circ} \mathrm{C}$ ) using iScript cDNA Synthesis Kit (Bio-Rad Laboratories, Hercules, CA, USA). $20 \mathrm{ng}$ of cDNA were incubated with a PCR mix $\left(2 \mathrm{~min}\right.$ at $50^{\circ} \mathrm{C}$, $10 \mathrm{~min}$ at $95^{\circ} \mathrm{C}$, followed by 40 cycles of $15 \mathrm{sec}$ at $95^{\circ} \mathrm{C}$ and $1 \mathrm{~min}$ at $60{ }^{\circ} \mathrm{C}$ ) including TaqMan Universal PCR Master Mix and TaqMan ${ }^{\circledR}$ Assays-on-Demand ${ }^{\mathrm{TM}}$ Gene Expression probes (Life Technologies) using the following assays: glyceraldehyde-3-phosphate dehydrogenase (GAPDH, Hs99999905_m1), peroxisome proliferatoractivated receptor gamma (PPARG, Hs01115513_m1), leptin (LEP, Hs00174877_m1), runt-related transcription factor $2\left(R U N X 2, \mathrm{Hs} 00 \overline{2} 31692 \_\mathrm{m} 1\right)$, collagen type I alpha 1(COL1A1, Hs01076777_m1), aggrecan (ACAN, Hs00153936_m1), SRY (Sex determining region Y)-box9 (SOX9, Hs00165814_m1), cartilage oligomeric matrix protein (COMP, Hs00164359_m1), collagen type II alpha I (COL2A1, Hs01060345_m1), collagen type X alpha 1 (COL10A1, Hs00166657_m1). The fold change in the expression of the different genes was normalised on the housekeeping GAPDH. 


\section{Statistical analysis}

Data are expressed as mean \pm standard error of the mean (SEM). Normal distribution of values was assessed by the Kolmogorov-Smirnov normality test. Statistical analysis was performed using Student's $t$-test and Wilcoxon test for paired data since IFP-MSCs and ASCs were obtained from the same donors; Student's $t$-test was used for data with a Gaussian distribution and Wilcoxon test for data with a non-Gaussian distribution (GraphPad Prism v5.00; GraphPad Software, San Diego, CA, USA). Level of significance was set at $p<0.05(* p<0.05$, ** $p<0.01$, $* * * p<0.001)$. The number of data used for the statistical analyses, indicated in figure legends as " $n$ ", corresponds to independent experiments performed with IFP-MSCs and ASCs isolated from " $n$ " individual donors, according to Ranstam (Ranstam, 2012).

\section{Results}

Undifferentiated IFP-MSCs and ASCs share common features and express a similar set of cell surface

\section{markers}

IFP-MSCs and ASCs displayed a fibroblastoid shape, which was maintained throughout the entire culture period, without any difference between the two cell types (Fig. 1a). From passage 1 to 4 , both cell populations displayed a high clonogenic ability (Fig. 1b,c), with a significantly higher clonogenic ability observed in IFP-MSCs compared to ASCs at passage $1(p<0.05)$.

As reported in Fig. 2a, both IFP-MSCs and ASCs analysed at passage 4 showed a similar immunophenotype, being positive for CD13, CD29, CD44, CD73, CD90, CD105, CD166 and negative for CD31 and CD45. For all the tested markers no difference was observed between IFP-MSCs and ASCs (Fig. 2b). A variable expression of CD34 and CD106 was found for IFP-MSCs and ASCs depending on the donor (10-35\% of positive cells). Both cell types expressed CD29, CD90, CD105, CD151 and CD166 (35-90\% of positive cells). A consistent expression of CD13, CD44 and CD73 was measured on IFP-MSCs and ASCs (90-100\% of positive cells).

\section{Adipogenic differentiation of IFP-MSCs and ASCs induces a similar upregulation of adipogenic markers except for leptin gene expression}

IFP-MSCs and ASCs cultured for 14 days in adipogenic medium showed the progressive loss of the fibroblastoidlike shape and the production of cytoplasmic lipid vacuoles, as evidenced by Oil Red $\mathrm{O}$ staining (Fig. 3a,b). The dye extraction revealed a significant increase in lipid vacuoles content in differentiated cells in comparison with cells in control medium $(p<0.001$ for IFP-MSCs and $p<0.05$ for ASCs) (Fig. 3c).

Gene expression analysis confirmed the ability of both cell types to respond to adipogenic induction. Indeed, a significant increase of PPARG expression was observed in IFP-MSCs $(p<0.05)$ and ASCs $(p<0.01)$ cultured in adipogenic medium in comparison with undifferentiated cells (Fig. 3d). Differentiated IFP-MSCs and ASCs showed also a significant up-regulation of $L E P$ expression, $(p<0.05$ and $p<0.01$, respectively) compared with undifferentiated cells. Finally, a significantly higher expression of $L E P$ was observed in differentiated ASCs in comparison with differentiated IFP-MSCs $(+295 \%$, $p<0.01)$.

\section{ASCs respond more efficiently to osteogenic induction in respect to IFP-MSCs}

Both IFP-MSCs and ASCs were able to differentiate towards the osteogenic lineage when cultured in osteoinductive medium, as demonstrated by the upregulation of specific markers such as calcified matrix, ALP activity, and transcriptional expression of RUNX2 and COL1A1 (Fig. 4).

Our results demonstrated that ASCs were more committed towards the osteogenic lineage compared with IFP-MSCs. Indeed, after 14 days of culture in osteogenic medium the deposition of calcified matrix was more consistent in differentiated ASCs (Fig. 4a) and the quantification of calcified matrix revealed a significant difference between the two cell populations $(+75 \%$ in ASCs, $p<0.05$, Fig. 4b). Furthermore, after 14 days of differentiation, ASCs produced significantly higher levels of ALP in comparison with IFP-MSCs $(+66 \%, p<0.05$, Fig. 4c).

After 21 days of osteogenic differentiation calcified matrix deposition and ALP levels were significantly increased in both cell populations compared to their correspondent controls. Comparing 14 and 21 days, we observed a significant increase of calcified matrix deposition in IFP-MSCs $(p<0.05)$ and ASCs $(p<0.01)$ over time. ALP levels were increased from 14 to 21 days in differentiated IFP-MSCs $(p<0.05)$, whereas this marker remained stable in ASCs. After 21 days of induction, we did not observe any significant difference between IFP-MSCs and ASCs in terms of calcified matrix deposition and ALP activity.

Higher expression of $R U N X 2$ and COL1A1 was observed both in undifferentiated and differentiated ASCs in comparison to their IFP-MSCs counterparts (Fig. 4d,e), with a significant difference in the expression of COL1A1 in undifferentiated cells $(+53 \%$ in ASCs, $p<0.05$, Fig. 4e).

\section{IFP-MSCs are more committed towards the chondrogenic lineage and express lower levels of hypertrophic and fibrocartilaginous markers as compared to ASCs}

After 14 days of chondrogenic induction in pellet culture conditions, histological evaluation revealed a superior and more homogeneous deposition of GAGs in IFPMSCs compared to ASCs pellets. As shown in Fig. 5, this difference was found in donors with different age, with some inter-donor variability.

No significant difference was observed in terms of DNA content, related to cell proliferation, between IFPMSCs and ASCs pellets, even if slightly higher values were measured in IFP-MSCs pellets (Fig. 6a). According to the histological results, a significantly higher amount of GAGs was measured in IFP-MSCs pellets, as demonstrated by 
the biochemical quantification $(+16 \%, p<0.01$, Fig. $6 \mathrm{~b})$. No significant difference was observed between the two populations in terms of GAGs/DNA ratio.

Accordingly with data obtained by histological and biochemical analyses, significantly higher levels of $A C A N$ gene expression were observed in IFP-MSCs pellets compared to ASCs pellets $(+474 \%, p<0.001$, Fig. 6c). Moreover, all the tested chondrogenic markers showed higher expression in IFP-MSCs (Fig. 6d-f), with significant differences for COMP $(+127 \%, p<0.001)$ and COL $2 A 1$ $(+728 \%, p<0.05)$ in comparison with ASCs.

The superior chondrogenic potential of IFP-MSCs compared to ASCs was confirmed also by data on hypertrophic and fibrocartilaginous markers (Fig. 6g,h): indeed, expression of COL10A1 and COL1A1 was significantly higher in ASCs in respect to IFP-MSCs $(+132 \%, p<0.05$ for COL10A1; $+75 \%, p<0.01$ for $C O L 1 A 1)$. Furthermore, in the early phase of chondrogenic differentiation (day 0 to day 3) ALP released from ASCs pellets was significantly higher in comparison with IFPMSCs pellets $(+119 \%, p<0.05$, Fig. 6i).

\section{Discussion}

The main finding of our study was the significantly different commitment of IFP-MSCs and ASCs in terms of differentiation ability; in particular, undifferentiated ASCs showed higher osteogenic potential in comparison with IFP-MSCs, whereas IFP-MSCs were characterised by superior chondrogenic ability. In our study both cell populations were isolated from the same knee of each patient, thus eliminating the bias of inter-donor variability and allowing a strict comparison of cell features, giving more consistent results. Furthermore, all the cells were derived from OA donors, in order not to neglect a possible impact of the pathological origin on cell features, in view of the possible future application of IFP-MSCs and ASCs in cell-based therapies designed to treat early OA patients. Indeed, in the quest to identify cells able to regenerate bone and cartilage damages and to develop new treatments for early OA patients, a major issue is to establish the ideal anatomical sites for autologous MSCs isolation. Both the fat depots investigated in this study are easily accessible during orthopaedic surgery and their harvesting causes a minimal discomfort and donor site morbidity, thus being ideal sources for the isolation of MSCs.

Undifferentiated IFP-MSCs and ASCs displayed similar features in terms of cell morphology, typically fibroblastoid. Both populations presented high clonogenic ability, with percentage of clonogenic cells ranging between 30 and $40 \%$, with IFP-MSCs forming a higher number of colonies compared to ASCs at passage 1 , in accordance with previously published data (Pires de Carvalho et al., 2012).

After in vitro expansion, the immunophenotype was coherent with the one reported in previous studies for IFP-MSCs and ASCs (Gronthos et al., 2001; Lee et al., 2004; Mochizuki et al., 2006; English et al., 2007; AlegreAguaron et al., 2012) and, in accordance with literature,

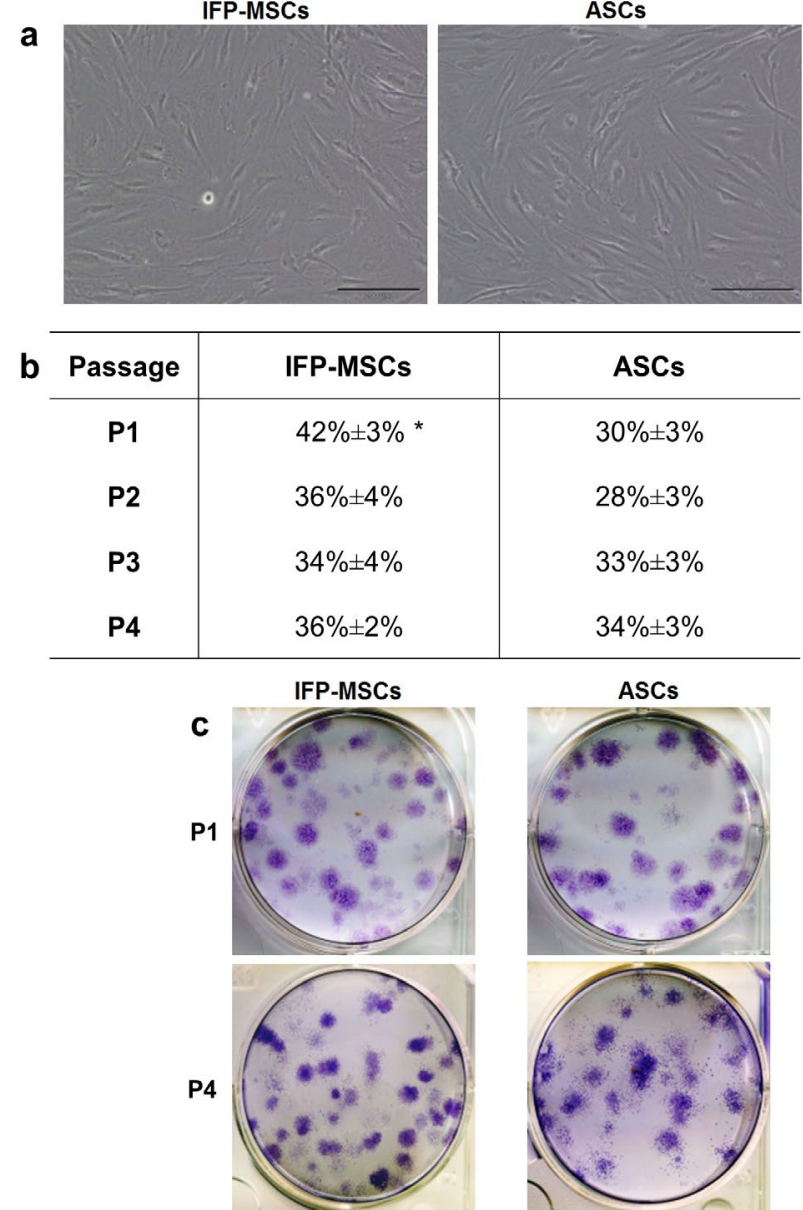

Fig. 1. Morphology and clonogenic potential of IFPMSCs and ASCs. (a) Cells in culture at passage 4 (scale bars $200 \mu \mathrm{m}$ ). (b) Percentage of clonogenic cells from passage 1 to passage 4 (scored colonies were normalised on number of seeded cells, $n=7, p<0.05)(\mathbf{c})$ Representative pictures of stained CFU-F at P1 and P4.

no difference was observed between the two populations (Alegre-Aguaron et al., 2012; Mochizuki et al., 2006).

Regarding the multilineage potential, both IFP-MSCs and ASCs were able to respond to the adipogenic stimuli, showing a similar induction of the characteristic adipogenic markers, but a significantly higher expression of $L E P$ was observed in undifferentiated ASCs in comparison with undifferentiated IFP-MSCs. Leptin is an inflammatory mediator which is mainly produced and secreted by adipocytes (Dumond et al., 2003; Fain, 2006). This adipokine stimulates IL-1 $\beta$ production, increases the effect of pro-inflammatory cytokines and induces the expression of matrix metalloproteinases which participate to cartilage matrix degradation in OA cartilage (Toussirot et al., 2007; Vuolteenaho et al., 2009). The significantly superior basal expression of $L E P$ in ASCs in respect to IFPMSCs is coherent published data, reporting a significantly higher production and secretion of this adipokine in the subcutaneous adipose tissue of OA patients compared to their infrapatellar fat pad (Distel et al., 2009). However, the same study also reported a superior secretion of IL-6 


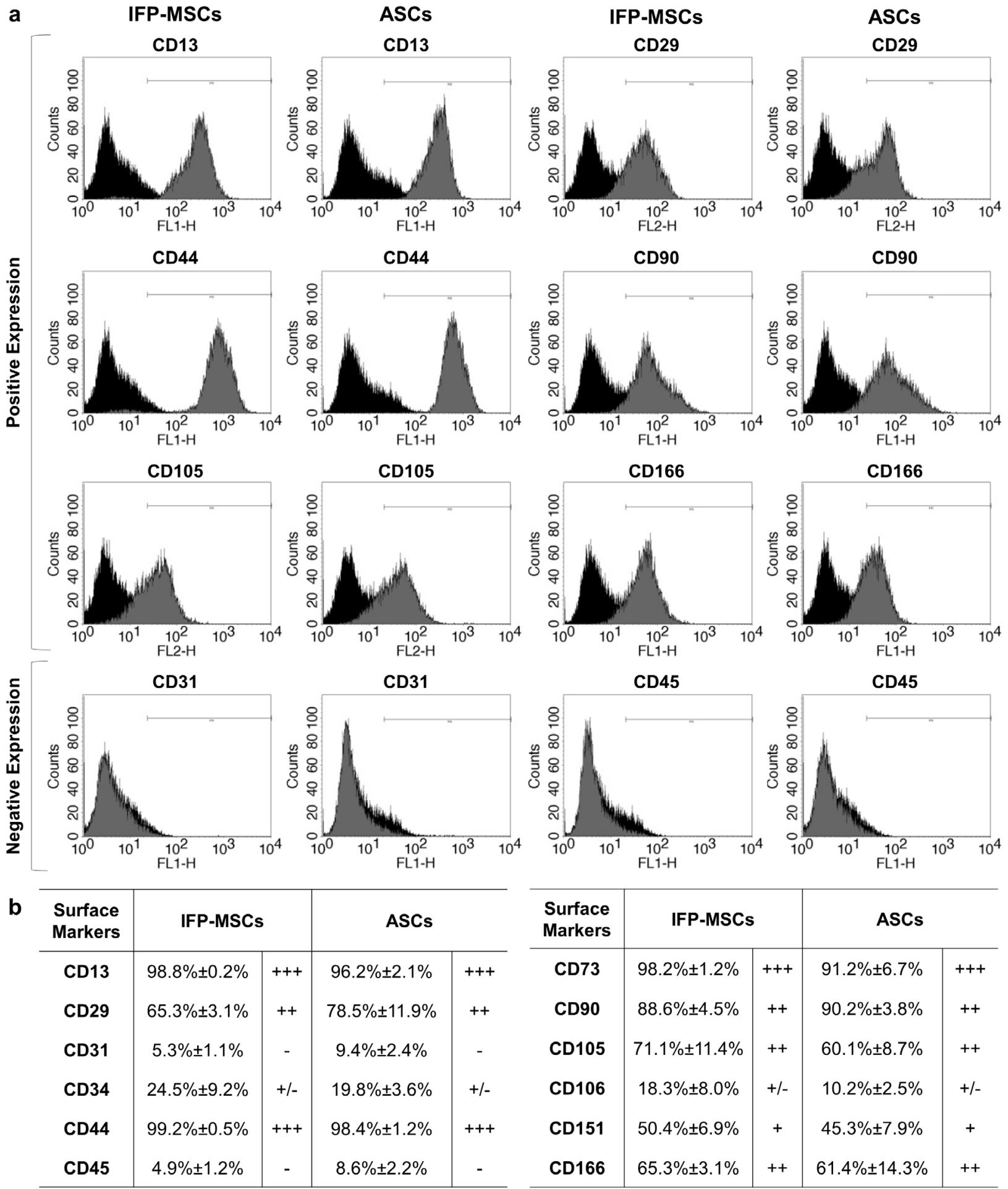

Fig. 2. Cell surface markers expression. (a) Representative expression of the typical MSCs surface markers pattern found in IFP-MSCs and ASCs from the same donor at passage 4 (markers are represented as grey histograms and isotype control antibodies are represented as black histograms). (b) Percentage of positive cells for the whole panel of surface markers tested in cells at passage $4(n=6)$. Ranking in table was established as: - for $0-10 \%,+/-$ for 10 $35 \%,+$ for $35-50 \%,++$ for $50-90 \%$, and +++ for $90-100 \%$ positive cells.

and its soluble receptor in infrapatellar fat pad compared to subcutaneous adipose tissue. The inflammatory profile of MSCs derived from both adipose depots would hence need further investigations to better define how these cell populations could react to the inflammatory state of OA joints, in view of their possible application in a future cellbased therapy.
Several studies have demonstrated the osteogenic and chondrogenic potential of IFP-MSCs (Dragoo et al., 2003; Wickham et al., 2003; English et al., 2007; Khan et al., 2009; Liu et al., 2012) and ASCs (Zuk et al., 2002; Gimble and Guilak, 2003; Guilak et al., 2004), but without comparing these cell populations. 

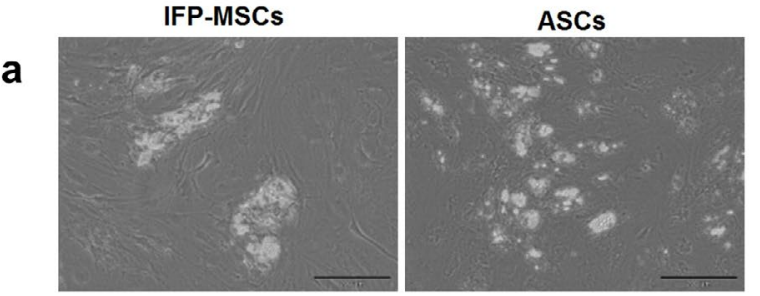

b
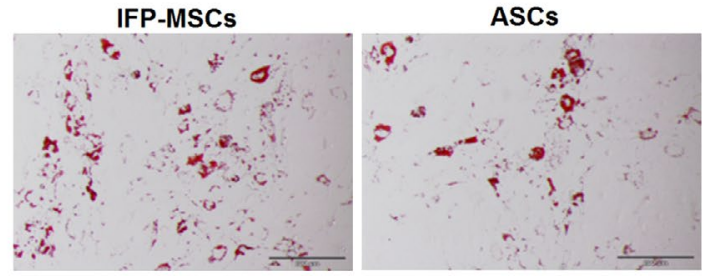

d

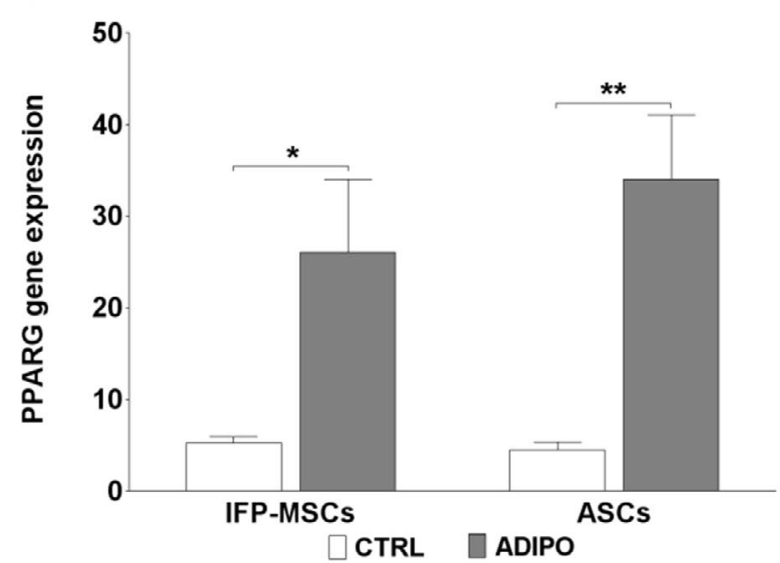

C

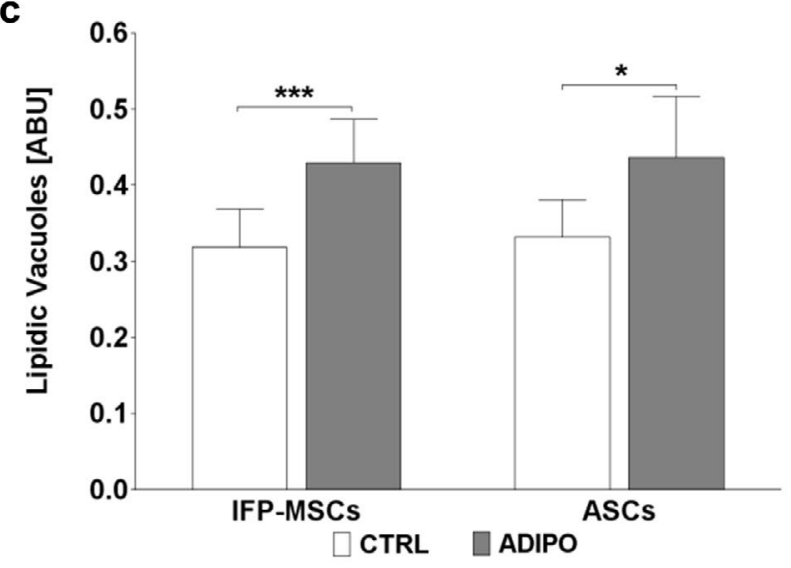

e

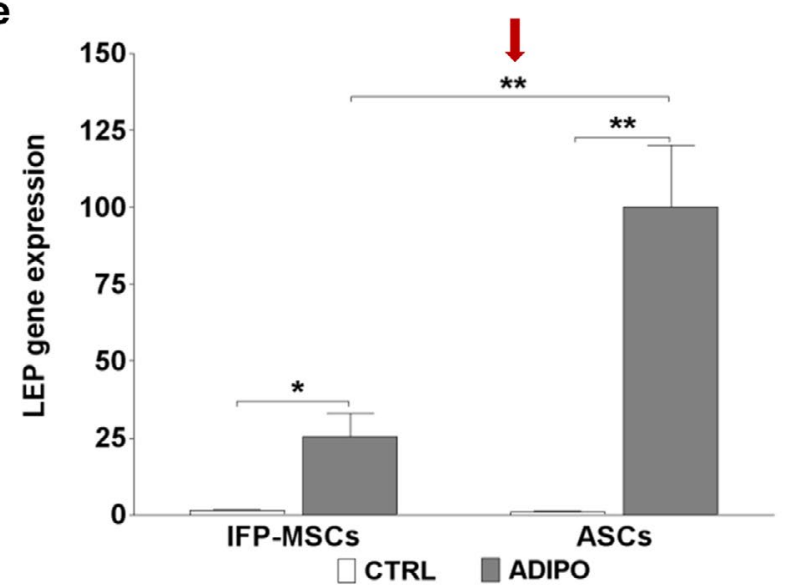

Fig. 3. Adipogenic differentiation. (a,b) Micrographs of IFP-MSCs and ASCs differentiated towards the adipogenic lineage during culture and after Oil Red O staining (scale bars $200 \mu \mathrm{m}$ ). (c) Quantification of lipid vacuoles in undifferentiated (CTRL) and adipogenic-differentiated (ADIPO) cells $(n=13)$. (d,e) Gene expression of PPARG and $L E P$ normalised to $G A P D H(n=7)$. Red arrow indicates a significant difference between IFP-MSCs and ASCs.

In our study, the direct donor-matched comparison between IFP-MSCs and ASCs through quantitative analyses allowed to observe important differences in their osteogenic and chondrogenic commitment. Significantly higher levels of ALP and calcified matrix deposition in osteo-induced ASCs compared to IFP-MSCs, together with the superior expression of COL1A1 in undifferentiated ASCs, demonstrated that ASCs are more committed towards the osteogenic lineage with respect to IFP-MSCs. These results differ from those described in previous studies whereby, on the basis of qualitative stainings, it has been reported that IFP-MSCs possess a similar (Pires de Carvalho et al., 2012) or higher (Mochizuki et al., 2006) osteogenic potential compared to ASCs. We believe that quantitative analyses and the inclusion of a more appropriate number of donors can give a higher sensitivity compared to qualitative staining, that could have led to such contrasting results compared to the current reported literature. Finally, differently from Mochizuki et al. (Mochizuki et al., 2006) that used as tissue source a mixture of synovium and adipose subsynovium, we carefully selected only the adipose fraction of infrapatellar fat pad prior to cell isolation to evaluate solely the differentiation potential of IFP-MSCs, which could also partially explain the different results obtained in our study.

On the other hand, a more pronounced chondrogenic commitment was found in IFP-MSCs compared to ASCs, as revealed by the significantly higher transcriptional expression of chondrogenic markers such as $A C A N$, $C O L 2 A 1$ and $C O M P$ in IFP-MSCs pellets. This result is in accordance with previously published results (AlegreAguaron et al., 2012), where the histological evaluation of pellets revealed that ASCs were characterised by lower chondrogenic ability compared to IFP-MSCs that displayed a chondrogenic phenotype more similar to the one of BMSCs. A superior chondrogenic potential in IFP-MSCs has also been described by Mochizuki et al. (2006) who, however, analysed expression of chondrogenic genes in pellets obtained from IFP-MSCs and ASCs from a single young non-OA donor. Our data, comprising GAGs quantification and gene expression analysis of cells derived from a larger number of old OA donors, support these literature data, providing an effective demonstration of the superior chondrogenic commitment of IFP-MSCs compared to ASCs, even when cells are obtained from osteoarthritic donors. 

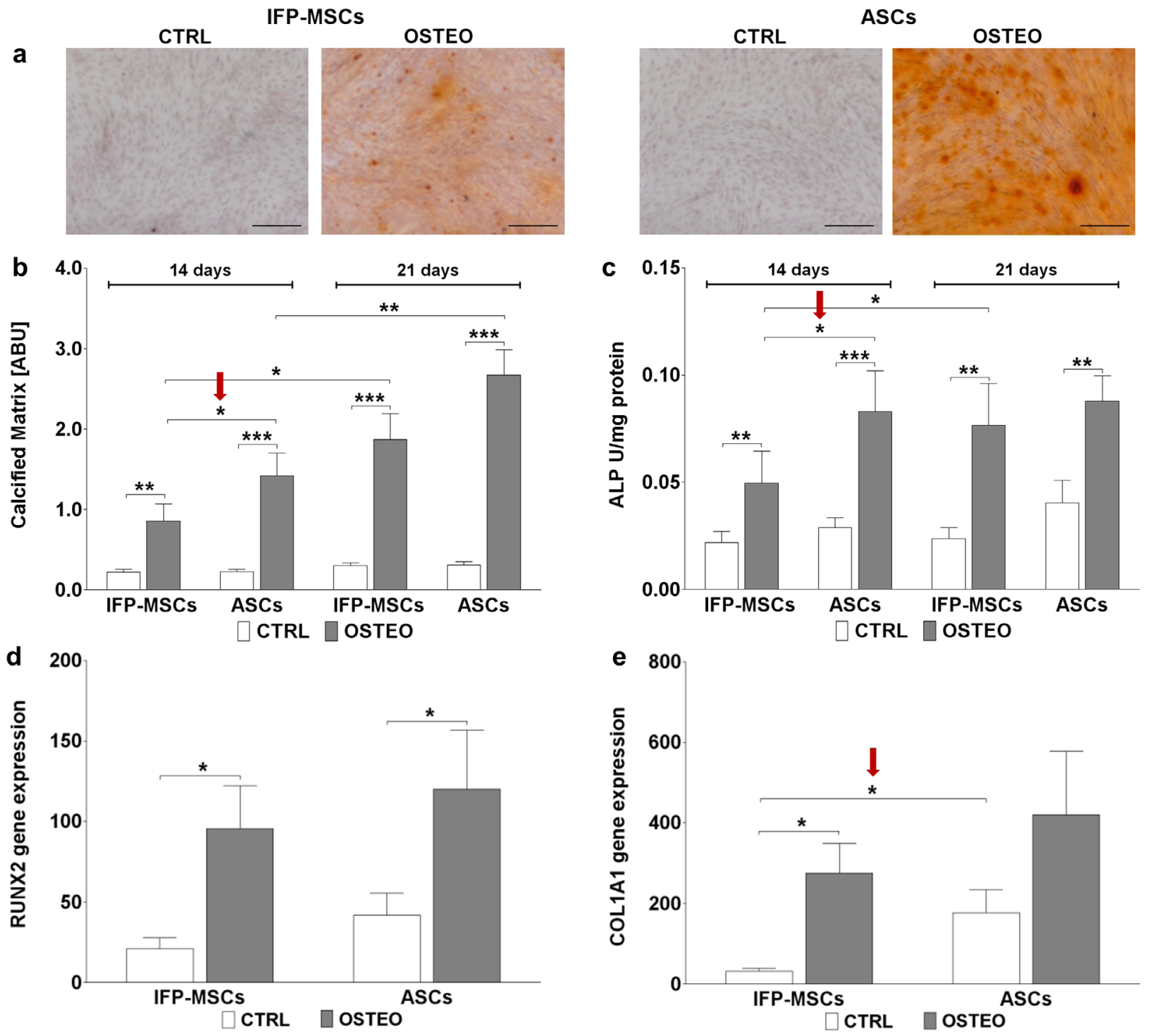

Fig. 4. Osteogenic differentiation. (a) Micrographs of IFP-MSCs and ASCs differentiated for 14 days and stained by AR-S (scale bars $500 \mu \mathrm{m}$ ). (b) Quantification of calcified matrix by AR-S staining and extraction in undifferentiated (CTRL) and osteogenic-differentiated (OSTEO) IFP-MSCs and ASCs $(n=14)$. (c) ALP activity determined by enzymatic assay and normalised by protein content $(n=9)$. (d,e) Gene expression of $R U N X 2$ and COL1A1 normalised to $\operatorname{GAPDH}(n=7)$. Red arrows indicate significant differences between IFP-MSCs and ASCs.

Furthermore, we investigated the expression of collagen $\mathrm{X}$ and alkaline phosphatase which are usually associated with the premature development of a hypertrophic phenotype during MSCs chondrogenesis (Ichinose et al., 2005; Mueller and Tuan, 2008; Pelttari et al., 2006; Winter et al., 2003). We found that, in the early phase of chondrogenic differentiation, release of ALP was significantly higher in ASCs pellets and that, after 14 days of chondrogenic differentiation, levels of COL10A1 were significantly lower in IFP-MSCs compared to ASCs, which may indicate a lower propensity of IFP-MSCs to develop a hypertrophic phenotype. Furthermore, we found that levels of $C O L 1 A 1$ were 50 -fold higher compared to transcriptional levels of $C O L 10 A 1$, which may indicate that both IFP-MSCs and ASCs are more prone to develop a fibrotic rather than a hypertrophic phenotype, as demonstrated for IFP-MSCs in a recent study (Vinardell et al., 2012).

The dissimilarities found between IFP-MSCs and ASCs may depend on the different anatomical localisation of infrapatellar fat pad and knee subcutaneous adipose tissue, considering that infrapatellar fat pad is in direct contact with synovial membrane and that the local tissue microenvironment could affect the commitment of MSCs. Differences in the expression of hypertrophic and fibrocartilaginous markers suggest that IFP-MSCs could be more suitable for cartilage applications aiming at the generation of specific cartilage-like matrix. However, further investigations after a longer period of chondrogenic differentiation are required to confirm the different trend between IFP-MSCs and ASCs in developing a hypertrophic phenotype. 

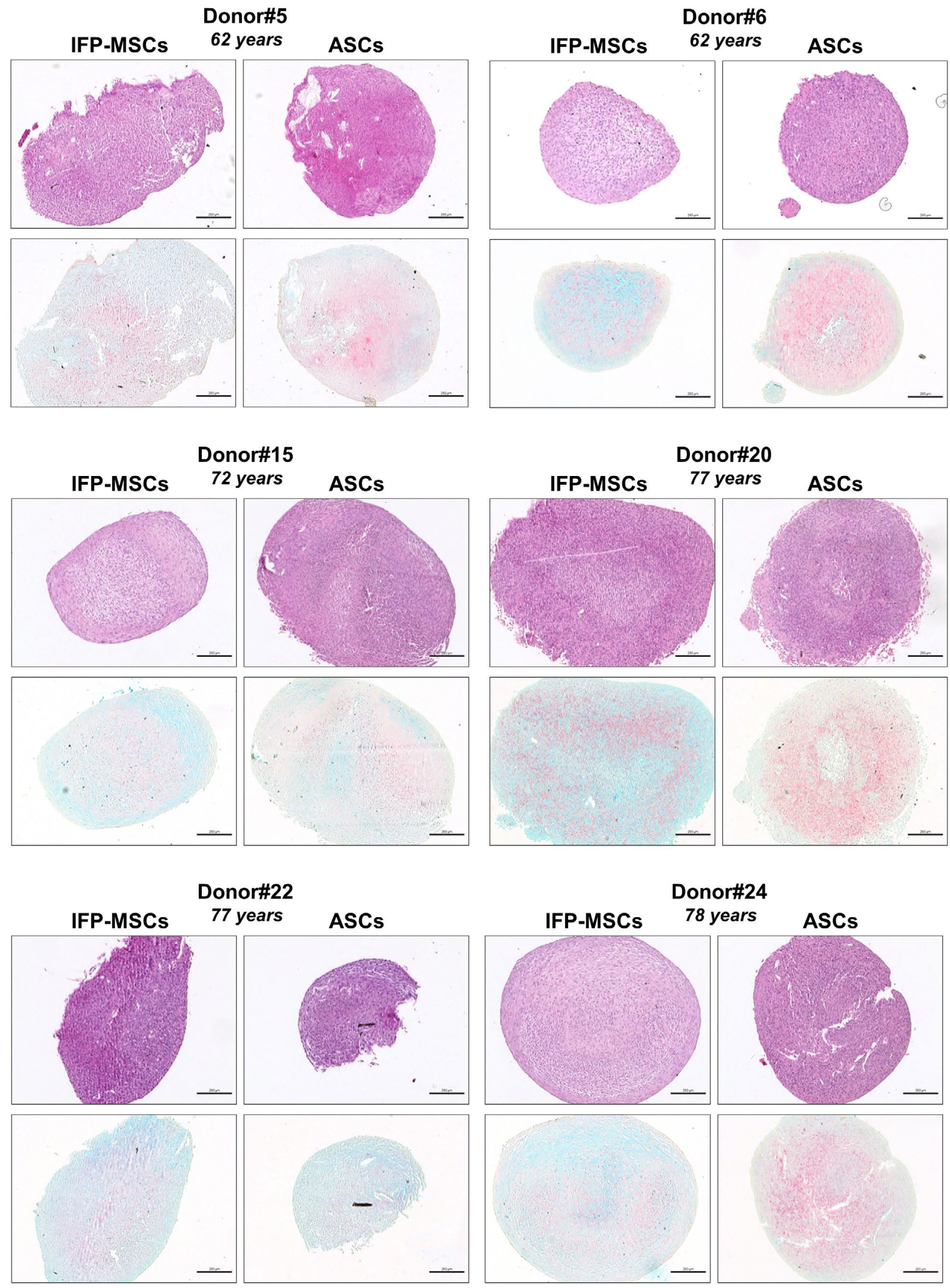

Fig. 5. Histological evaluation of pellets from different donors. Haematoxylin-eosin and alcian blue staining of pellets prepared with IFP-MSCs and ASCs derived from younger and older donors (scale bars, $200 \mu \mathrm{m}$ ). 

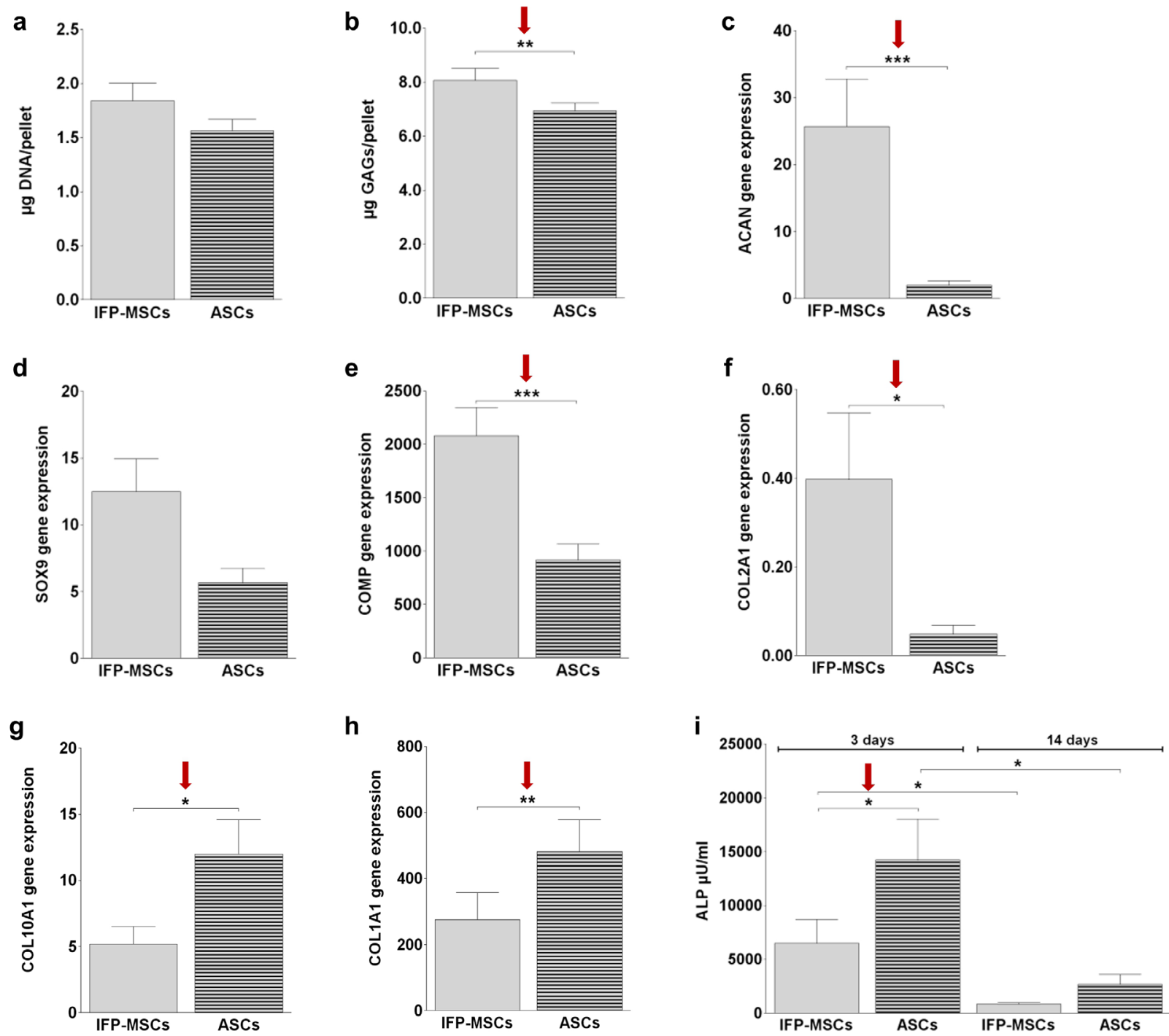

Fig. 6. Chondrogenic differentiation. (a,b) DNA and GAGs content in IFP-MSCs and ASCs pellets $(n=15)$. (c-h) Gene expression of ACAN, SOX9, COMP, COL2A1, COL10A1 and COL1A1 normalised to GAPDH $(n=10)$. (i) Soluble ALP activity released in culture supernatants from day 0 to day 3 (indicated as 3 days) and from day 11 to day 14 (indicated as 14 days) $(n=8)$. Red arrows indicate significant differences between IFP-MSCs and ASCs.

Despite similar surface markers expression in the undifferentiated state, different populations of MSCs can display significantly different commitment towards specific cell lineages. This supports the importance of introducing more specific and predictive markers to identify which population of MSCs could be more suitable for a specific clinical application. as proposed by recent studies that have investigated the differentiation potential of specific subsets of MSCs (Jiang et al., 2010; Quirici et al., 2010; Kim et al., 2012).

It should be highlighted that the differential commitment of IFP-MSCs and ASCs emerged from in vitro experiments and should be further confirmed through in vivo studies to better validate the clinical relevance of our data. However, our results contribute to show how quantitative analyses on larger donor populations are fundamental for a more reliable characterisation of primary human cells, contributing to build a more consistent base for cell-based therapies.

\section{Conclusions}

To the best of our knowledge, this is the first study to compare donor-matched IFPs and ASCs from such a large number of OA donors, characterising their osteogenic and chondrogenic potential through several quantitative analyses. This provided novel and interesting insights on their specific differentiation capabilities, opening to a more rational selection as preferential sources for regenerating cartilage and bone tissues or developing osteochondral treatments, aimed at future clinical cell-based treatments, also in OA patients.

\section{Acknowledgements}

The authors would like to thank L. J. Turner and C. Bonora for their contribution in the experiments and in the harvesting of human biopsies. This study was supported 
by the Italian Ministry of Health that contributed solely in terms of financial support to the study.

\section{References}

Alegre-Aguaron E, Desportes P, Garcia-Alvarez F, Castiella T, Larrad L, Martinez-Lorenzo MJ (2012) Differences in surface marker expression and chondrogenic potential among various tissue-derived mesenchymal cells from elderly patients with osteoarthritis. Cells Tissues Organs 196: 231-240.

Barbero A, Grogan S, Schafer D, Heberer M, MainilVarlet P, Martin I (2004) Age related changes in human articular chondrocyte yield, proliferation and postexpansion chondrogenic capacity. Osteoarthritis Cartilage 12: 476-484.

Beane OS, Darling EM(2012) Isolation, characterization, and differentiation of stem cells for cartilage regeneration. Ann Biomed Eng 40: 2079-2097.

Bodo M, Lilli C, Bellucci C, Carinci P, Calvitti M, Pezzetti F, Stabellini G, Bellocchio S, Balducci C, Carinci F, Baroni T (2002) Basic fibroblast growth factor autocrine loop controls human osteosarcoma phenotyping and differentiation. Mol Med 8: 393-404.

Choi JW, Park EJ, Shin HS, Shin IS, Ra JC, Koh KS (2014) In vivo differentiation of undifferentiated human adipose tissue-derived mesenchymal stem cells in criticalsized calvarial bone defects. Ann Plast Surg 72: 225-233.

de Girolamo L, Lopa S, Arrigoni E, Sartori MF, Baruffaldi Preis FW, Brini AT (2009) Human adiposederived stem cells isolated from young and elderly women: their differentiation potential and scaffold interaction during in vitro osteoblastic differentiation. Cytotherapy 11: 793-803.

Desando G, Cavallo C, Sartoni F, Martini L, Parrilli A, Veronesi F, Fini M, Giardino R, Facchini A, Grigolo B (2013) Intra-articular delivery of adipose derived stromal cells attenuates osteoarthritis progression in an experimental rabbit model. Arthritis Res Ther 15: R22.

Distel E, Cadoudal T, Durant S, Poignard A, Chevalier X, Benelli C (2009) The infrapatellar fat pad in knee osteoarthritis: an important source of interleukin-6 and its soluble receptor. Arthritis Rheum 60: 3374-3377.

Dragoo JL, Samimi B, Zhu M, Hame SL, Thomas BJ, Lieberman JR, Hedrick MH, Benhaim P (2003) Tissueengineered cartilage and bone using stem cells from human infrapatellar fat pads. J Bone Joint Surg Br 85: 740-747.

Dumond H, Presle N, Terlain B, Mainard D, Loeuille D, Netter P, Pottie P (2003) Evidence for a key role of leptin in osteoarthritis. Arthritis Rheum 48: 3118-3129.

English A, Jones EA, Corscadden D, Henshaw K, Chapman T, Emery P, McGonagle D (2007) A comparative assessment of cartilage and joint fat pad as a potential source of cells for autologous therapy development in knee osteoarthritis. Rheumatology (Oxford) 46: 1676-1683.

Fain JN (2006) Release of interleukins and other inflammatory cytokines by human adipose tissue is enhanced in obesity and primarily due to the nonfat cells. Vitam Horm 74: 443-477.
Gimble JM, Guilak F (2003) Differentiation potential of adipose derived adult stem (ADAS) cells. Curr Top Dev Biol 58: 137-160.

Gomoll AH, Filardo G, Almqvist FK, Bugbee WD, Jelic M, Monllau JC, Puddu G, Rodkey WG, Verdonk P, Verdonk R, Zaffagnini S, Marcacci M (2012) Surgical treatment for early osteoarthritis. Part II: allografts and concurrent procedures. Knee Surg Sports Traumatol Arthrosc 20: 468-486.

Gronthos S, Franklin DM, Leddy HA, Robey PG, Storms RW, Gimble JM (2001) Surface protein characterization of human adipose tissue-derived stromal cells. J Cell Physiol 189: 54-63.

Guilak F, Awad HA, Fermor B, Leddy HA, Gimble JM (2004) Adipose-derived adult stem cells for cartilage tissue engineering. Biorheology 41: 389-399.

Harrysson OL, Robertsson O, Nayfeh JF (2004) Higher cumulative revision rate of knee arthroplasties in younger patients with osteoarthritis. Clin Orthop Relat Res: 162168.

Ichinose S, Yamagata K, Sekiya I, Muneta T, Tagami M (2005) Detailed examination of cartilage formation and endochondral ossification using human mesenchymal stem cells. Clin Exp Pharmacol Physiol 32: 561-570.

Jiang T, Liu W, Lv X, Sun H, Zhang L, Liu Y, Zhang WJ, Cao Y, Zhou G (2010) Potent in vitro chondrogenesis of CD105 enriched human adipose-derived stem cells. Biomaterials 31: 3564-3571.

Johnstone B, Hering TM, Caplan AI, Goldberg VM, Yoo JU (1998) In vitro chondrogenesis of bone marrowderived mesenchymal progenitor cells. Exp Cell Res 238: 265-272.

Julin J, Jamsen E, Puolakka T, Konttinen YT, Moilanen $\mathrm{T}$ (2010) Younger age increases the risk of early prosthesis failure following primary total knee replacement for osteoarthritis. A follow-up study of 32,019 total knee replacements in the Finnish Arthroplasty Register. Acta Orthop 81: 413-419.

Jung SN, Rhie JW, Kwon H, Jun YJ, Seo JW, Yoo G, Oh DY, Ahn ST, Woo J, Oh J (2010) In vivo cartilage formation using chondrogenic-differentiated human adipose-derived mesenchymal stem cells mixed with fibrin glue. J Craniofac Surg 21: 468-472.

Kang H, Peng J, Lu S, Liu S, Zhang L, Huang J, Sui $\mathrm{X}$, Zhao B, Wang A, Xu W, Luo Z, Guo Q (2012) In vivo cartilage repair using adipose-derived stem cell-loaded decellularized cartilage ECM scaffolds. J Tissue Eng Regen Med, in press.

Khan WS, Adesida AB, Tew SR, Andrew JG, Hardingham TE (2009) The epitope characterisation and the osteogenic differentiation potential of human fat padderived stem cells is maintained with ageing in later life. Injury 40: 150-157.

Kim YH, Yoon DS, Kim HO, Lee JW (2012) Characterization of different subpopulations from bone marrow-derived mesenchymal stromal cells by alkaline phosphatase expression. Stem Cells Dev 21: 2958-2968.

Koh YG, Jo SB, Kwon OR, Suh DS, Lee SW, Park SH, Choi YJ (2013) Mesenchymal stem cell injections improve symptoms of knee osteoarthritis. Arthroscopy 29: 748-755. 
Lee RH, Kim B, Choi I, Kim H, Choi HS, Suh K, Bae YC, Jung JS (2004) Characterization and expression analysis of mesenchymal stem cells from human bone marrow and adipose tissue. Cell Physiol Biochem 14: 311-324.

Liu Y, Buckley CT, Downey R, Mulhall KJ, Kelly DJ (2012) The role of environmental factors in regulating the development of cartilaginous grafts engineered using osteoarthritic human infrapatellar fat pad-derived stem cells. Tissue Eng Part A 18: 1531-1541.

Lopa S, Colombini A, de Girolamo L, Sansone V, Moretti M (2011) New strategies in cartilage tissue engineering for osteoarthritic patients: Infrapatellar fat pad as an alternative source of progenitor cells. J Biomater Tissue Eng 1: 40-48.

Lopez-Ruiz E, Peran M, Cobo-Molinos J, Jimenez G, Picon M, Bustamante M, Arrebola F, HernandezLamas MC, Delgado-Martinez AD, Montanez E, Marchal JA (2013) Chondrocytes extract from patients with osteoarthritis induces chondrogenesis in infrapatellar fat pad-derived stem cells. Osteoarthritis Cartilage 21: 246258.

Mochizuki T, Muneta T, Sakaguchi Y, Nimura A, Yokoyama A, Koga H, Sekiya I (2006) Higher chondrogenic potential of fibrous synovium- and adipose synovium-derived cells compared with subcutaneous fatderived cells: distinguishing properties of mesenchymal stem cells in humans. Arthritis Rheum 54: 843-853.

Mohal JS, Tailor HD, Khan WS (2012) Sources of adult mesenchymal stem cells and their applicability for musculoskeletal applications. Curr Stem Cell Res Ther 7: 103-109.

Mueller MB, Tuan RS (2008) Functional characterization of hypertrophy in chondrogenesis of human mesenchymal stem cells. Arthritis Rheum 58: 1377-1388.

Pelttari K, Winter A, Steck E, Goetzke K, Hennig T, Ochs BG, Aigner T, Richter W (2006) Premature induction of hypertrophy during in vitro chondrogenesis of human mesenchymal stem cells correlates with calcification and vascular invasion after ectopic transplantation in SCID mice. Arthritis Rheum 54: 3254-3266.

Pires de Carvalho P, Hamel KM, Duarte R, King AG, Haque M, Dietrich MA, Wu X, Shah F, Burk D, Reis RL, Rood J, Zhang P, Lopez M, Gimble JM, Dasa V (2012) Comparison of infrapatellar and subcutaneous adipose tissue stromal vascular fraction and stromal/stem cells in osteoarthritic subjects. J Tissue Eng Regen Med, in press.

Pittenger MF, Mackay AM, Beck SC, Jaiswal RK, Douglas R, Mosca JD, Moorman MA, Simonetti DW, Craig S, Marshak DR (1999) Multilineage potential of adult human mesenchymal stem cells. Science 284: 143-147.

Quirici N, Scavullo C, de Girolamo L, Lopa S, Arrigoni E, Deliliers GL, Brini AT (2010) Anti-L-NGFR and -CD34 monoclonal antibodies identify multipotent mesenchymal stem cells in human adipose tissue. Stem Cells Dev 19: 915-925.

Rada T, Reis RL, Gomes ME (2009) Adipose tissuederived stem cells and their application in bone and cartilage tissue engineering. Tissue Eng Part B Rev 15: 113-125.
Ranstam J (2012) Repeated measurements, bilateral observations and pseudoreplicates, why does it matter? Osteoarthritis Cartilage 20: 473-475.

Rhee SC, Ji YH, Gharibjanian NA, Dhong ES, Park $\mathrm{SH}$, Yoon ES (2011) In vivo evaluation of mixtures of uncultured freshly isolated adipose-derived stem cells and demineralized bone matrix for bone regeneration in a rat critically sized calvarial defect model. Stem Cells Dev 20: 233-242.

Staszkiewicz J, Frazier TP, Rowan BG, Bunnell BA, Chiu ES, Gimble JM, Gawronska-Kozak B (2010) Cell growth characteristics, differentiation frequency, and immunophenotype of adult ear mesenchymal stem cells. Stem Cells Dev 19: 83-92.

Szpalski C, Barbaro M, Sagebin F, Warren SM (2012) Bone tissue engineering: current strategies and techniques - part II: Cell types. Tissue Eng Part B Rev 18: 258-269.

ter Huurne M, Schelbergen R, Blattes R, Blom A, de Munter W, Grevers LC, Jeanson J, Noel D, Casteilla L, Jorgensen C, van den Berg W, van Lent PL (2012) Antiinflammatory and chondroprotective effects of intraarticular injection of adipose-derived stem cells in experimental osteoarthritis. Arthritis Rheum 64: 36043613.

Toghraie F, Razmkhah M, Gholipour MA, Faghih Z, Chenari N, Torabi Nezhad S, Nazhvani Dehghani S, Ghaderi A (2012) Scaffold-free adipose-derived stem cells (ASCs) improve experimentally induced osteoarthritis in rabbits. Arch Iran Med 15: 495-499.

Toghraie FS, Chenari N, Gholipour MA, Faghih Z, Torabinejad S, Dehghani S, Ghaderi A (2011) Treatment of osteoarthritis with infrapatellar fat pad derived mesenchymal stem cells in Rabbit. Knee 18: 71-75.

Toussirot E, Streit G, Wendling D (2007) The contribution of adipose tissue and adipokines to inflammation in joint diseases. Curr Med Chem 14: 10951100.

Vinardell T, Sheehy EJ, Buckley CT, Kelly DJ (2012) A comparison of the functionality and in vivo phenotypic stability of cartilaginous tissues engineered from different stem cell sources. Tissue Eng Part A 18: 1161-1170.

Vuolteenaho K, Koskinen A, Kukkonen M, Nieminen R, Paivarinta U, Moilanen T, Moilanen E (2009) Leptin enhances synthesis of proinflammatory mediators in human osteoarthritic cartilage - mediator role of NO in leptin-induced PGE2, IL-6, and IL-8 production. Mediators Inflamm 2009: 345838.

Wickham MQ, Erickson GR, Gimble JM, Vail TP, Guilak F (2003) Multipotent stromal cells derived from the infrapatellar fat pad of the knee. Clin Orthop Relat Res: 196-212.

Winter A, Breit S, Parsch D, Benz K, Steck E, Hauner H, Weber RM, Ewerbeck V, Richter W (2003) Cartilagelike gene expression in differentiated human stem cell spheroids: a comparison of bone marrow-derived and adipose tissue-derived stromal cells. Arthritis Rheum 48: 418-429.

Zuk PA, Zhu M, Ashjian P, De Ugarte DA, Huang JI, Mizuno H, Alfonso ZC, Fraser JK, Benhaim P, Hedrick MH (2002) Human adipose tissue is a source of multipotent stem cells. Mol Biol Cell 13: 4279-4295. 


\section{Discussion with Reviewers}

A. Barbero: The authors showed that IFP-MSCs cultured with medium containing TGF $\beta$ produced better cartilaginous tissues than ASCs. It is, however, known that adipose derived MSC (as compared to bone marrowderived MSC) required BMP-6 in order to chondrodifferentiate. Did the authors try to culture ASCs with different chondrogenic cocktails?

Authors: In this study, we observed superior deposition of GAGs and superior expression of chondrogenic markers in IFP-MSCs pellets compared to donor-matched ASCs pellets. Due to the limited amount of cells that can be obtained from each patient, we were able to test only a single formulation of chondrogenic medium. However, in a previous study comparing donor-matched IFP-MSCs and ASCs from OA patients (Alegre-Aguaron et al., 2012, text reference) the superior chondrogenic potential of IFPMSCs in comparison with ASCs was observed even when combining TGF $\beta$ and BMP-6 to induce chondrogenic differentiation, as revealed by the histological scoring. Our results confirm this finding, suggesting that the differences observed between the two cell populations are independent from the presence of BMP- 6 in the chondrogenic medium formulation.

A. Barbero: Due to its important role in the joint homeostasis, IFP tissue cannot be harvested in large quantity. What is the amount of IFP tissue that can be harvested from a knee in order to get enough MSC for possible clinical application?

Authors: In our experience it is possible to harvest up to $40 \%$ of the entire infrapatellar fat pad volume, which in total measures about 20-25 $\mathrm{cm}^{3}$ (Chuckpaiwong et al., 2010, additional reference), without impairing joint function. In our experiments, samples ranged from 3 to $10 \mathrm{~cm}^{3}$ (average volume $5.8 \mathrm{~cm}^{3}$ ) and cell isolation yielded about $1 \times 10^{5}-1.5 \times 10^{5}$ cells $/ \mathrm{mL}$, with some donordependent variations. Our data are in accordance with results from a recent study where IFP-MSCs were isolated from infrapatellar fat pad (average weight $9.4 \mathrm{~g}$; range, 6.9-11.2 g; average number of cells/sample $1.89 \times 10^{6}$; range $1.2 \times 10^{6}-2.3 \times 10^{6}$ cells/sample) and immediately injected back in the patients in combination with Platelet Rich Plasma (PRP) for the treatment of knee OA, showing an improvement in symptoms compared to patients treated with PRP only (Koh et al., 2012, additional reference). This study, together with a follow-up study (Koh et al., 2013, additional reference), has demonstrated that even a limited number of IFP-MSCs can improve knee OA symptoms, reporting no adverse effect deriving from the infrapatellar fat pad harvesting. Hence, we believe that this adipose depot represents a promising cell source for future cell-based applications, even considering the possibility to use IFP-MSCs in combination with autologous articular chondrocytes thus eliminating, or at least reducing, the duration of in vitro cell expansion prior to re-implantation.

D. Kelly: BMP-6 has been shown to be critical for chondrogenesis of ASCs (Estes et al., 2006; Hennig et al., 2007). Do the authors believe that the enhanced chondrogenesis observed here in IFP-MSCs compared to ASCs would be replicated in alternative media formulations additionally supplemented with BMP-6? Is there evidence from the literature to suggest that the chondrogenic capacity of IFP-MSCs is also enhanced in the presence of BMP-6?

Authors: In a previous study comparing donor-matched IFP-MSCs and ASCs from OA patients (Alegre-Aguaron et al., 2012, text reference) the superior chondrogenic potential of IFP-MSCs was observed even using a chondrogenic medium containing both TGF $\beta$ and BMP6 , suggesting that the differences between the two cell populations are independent of the presence of BMP-6. We found in the literature only few studies reporting the use of BMP-6 for the chondrogenic induction of human IFP-MSCs (Alegre-Aguaron et al., 2012, text reference; Felimban et al., 2014, additional reference). However, in these studies a comparison between medium formulations with TGF $\beta$ only and TGF $\beta$ combined with BMP6 is not present, which does not allow us to verify whether BMP-6 enhances the chondrogenic ability of this cell population. A recent study, performed using porcine IFP-MSCs, has shown that the simultaneous use of TGF $\beta$ and BMP-6 is able to improve the chondrogenic differentiation of IFPMSCs, compared to cells differentiated in the presence of TGF $\beta$ alone (He et al., 2013, additional reference). However, this improvement was not observed in cells differentiated after several passages in culture, suggesting that the chondrogenic effect of BMP-6 may be influenced by the duration of IFP-MSCs expansion phase prior to chondrogenic differentiation.

D. Kelly: The authors use differences in ALP and collagen $\mathrm{X}$ expression to suggest that IFP-MSCs may have a lower tendency towards hypertrophy. It has been shown that in vivo, cartilage tissues engineered using IFP derived stem cells undergo fibro-cartilaginous or fibrous dedifferentiation rather than progressing along an endochondral route (Vinardell et al., 2012). This raises a question as to whether type $\mathrm{X}$ collagen expression and ALP are appropriate markers for accessing the ability of IFP-MSCs to generate stable cartilage tissue. Can the authors comment on this and whether they believe their cartilage pellets are proceeding along an endochondral or an alternative pathway.

Authors: In our experiments we found that the transcriptional expression of COL1A1 was 50-fold higher compared to transcriptional levels of COL10A1, which may suggest that cells are developing a fibrous phenotype rather than progressing towards an endochondral pathway. However, in our study a short time point was chosen to evaluate the chondrogenic differentiation of IFP-MSCs and ASCs and we did not monitor the kinetic of COL1A1 and COL10A1 expression over time to confirm this hypothesis.

In the study by Vinardell and co-workers (Vinardell et al., 2012, text reference), one of the main differences between porcine bone marrow MSCs and IFP-MSCs seem to be the ability to generate calcified matrix after 49 days of in vitro culture. Hence, this parameter could be evaluated in cells differentiated over a long period of time to verify this hypothesis in human cells and to highlight 
possible differences between IFP-MSCs and ASCs in the development of a fibrous rather than a hypertrophic phenotype.

\section{Additional References}

Chuckpaiwong B, Charles HC, Kraus VB, Guilak F, Nunley JA (2010) Age-associated increases in the size of the infrapatellar fat pad in knee osteoarthritis as measured by 3 T MRI. J Orthop Res 28: 1149-1154.

Felimban R, Ye K, Traianedes K, Di Bella C, Crook J, Wallace GG, Quigley AF, Choong PF, Myers D (2014)
Differentiation of stem cells from human infrapatellar fat pad: Characterization of cells undergoing chondrogenesis. Tissue Eng Part A, in press.

He F, Pei M (2013) Extracellular matrix enhances differentiation of adipose stem cells from infrapatellar fat pad toward chondrogenesis. J Tissue Eng Regen Med 7: 73-84.

Koh YG, Choi YJ (2012) Infrapatellar fat pad-derived mesenchymal stem cell therapy for knee osteoarthritis. Knee 19: 902-907.

Koh YG, Jo SB, Kwon OR, Suh DS, Lee SW, Park SH, Choi YJ (2013) Mesenchymal stem cell injections improve symptoms of knee osteoarthritis. Arthroscopy 29: 748-755. 